\title{
CD206-Targeted Liposomal Myelin Basic Protein Peptides in Patients with Multiple Sclerosis Resistant to First-Line Disease-Modifying Therapies: A First-in-Human, Proof-of-Concept Dose-Escalation Study
}

\author{
Alexey Belogurov Jr. ${ }^{1,2,3} \cdot$ Konstantin Zakharov $^{4}$ - Yakov Lomakin ${ }^{1,2} \cdot$ Kirill Surkov $^{4}$. \\ Sergey Avtushenko ${ }^{4}$ Peter Kruglyakov ${ }^{4}$ - Ivan Smirnov ${ }^{1,2}$ • Gleb Makshakov ${ }^{5,6}$. \\ Curtis Lockshin $^{7}$ • Gregory Gregoriadis ${ }^{7}$ • Dmitry Genkin ${ }^{4}$ • Alexander Gabibov ${ }^{1,2,8}$. \\ Evgeniy Evdoshenko ${ }^{5,6,9}$
}

Published online: 20 June 2016

(C) The Author(s) 2016. This article is published with open access at Springerlink.com

\begin{abstract}
Previously, we showed that CD206-targeted liposomal delivery of co-encapsulated immunodominant myelin basic protein (MBP) sequences $\mathrm{MBP}_{46-62}, \mathrm{MBP}_{124-139}$ and $\mathrm{MBP}_{147-170}$ (Xemys) suppressed experimental autoimmune encephalomyelitis in dark Agouti rats. The objective of this study was to assess the safety of Xemys in the treatment of patients with relapsing-remitting multiple sclerosis (MS) and secondary progressive MS, who failed to achieve a sustained response to first-line disease-modifying therapies. In this
\end{abstract}

Electronic supplementary material The online version of this article (doi:10.1007/s13311-016-0448-0) contains supplementary material, which is available to authorized users.

Alexander Gabibov

gabibov@mx.ibch.ru

1 M.M. Shemyakin and Yu.A. Ovchinnikov Institute of Bioorganic Chemistry, Russian Academy of Sciences, Moscow, Russia

2 Institute of Fundamental Medicine and Biology, Kazan Federal University, Kazan, Tatarstan, Russia

3 Institute of Gene Biology RAS, Moscow, Russia

4 OJSC Pharmsynthez, St. Petersburg, Russia

5 Center of multiple sclerosis and AID of St. Petersburg City Clinical Hospital \#31, St. Petersburg, Russia

6 Pavlov First Saint-Petersburg State Medical University, St. Petersburg, Russia

7 Xenetic Biosciences Inc., Lexington, MA, USA

8 Chemistry Department of Moscow State University, Moscow, Russia

9 SBI "Center of Clinical Trials Management and Performance of Moscow Department of Healthcare”, Moscow, Russia phase I, open-label, dose-escalating, proof-of-concept study, 20 patients with relapsing-remitting or secondary progressive MS received weekly subcutaneously injections with ascending doses of Xemys up to a total dose of $2.675 \mathrm{mg}$. Clinical examinations, including Expanded Disability Status Scale score, magnetic resonance imaging results, and serum cytokine concentrations, were assessed before the first injection and for up to 17 weeks after the final injection. Xemys was safe and well tolerated when administered for 6 weeks to a maximum single dose of $900 \mu \mathrm{g}$. Expanded Disability Status Scale scores and numbers of $\mathrm{T} 2$-weighted and new gadolinium-enhancing lesions on magnetic resonance imaging were statistically unchanged at study exit compared with baseline; nonetheless, the increase of number of active gadolinium-enhancing lesions on weeks 7 and 10 in comparison with baseline was statistically significant. During treatment, the serum concentrations of the cytokines monocyte chemoattractant protein-1, macrophage inflammatory protein- $1 \beta$, and interleukin- 7 decreased, whereas the level of tumor necrosis factor- $\alpha$ increased. These results provide evidence for the further development of Xemys as an antigenspecific, disease-modifying therapy for patients with MS.

Keywords Clinical trial · MRI · Myelin basic protein · Liposomes $\cdot$ Xemys $\cdot$ Mannose

\section{Introduction}

Multiple sclerosis (MS) is a chronic neurodegenerative disease with an evident autoimmune background resulting in inflammatory demyelination and axonal and neuronal injury 
[1]. MS, which was first described in 1868 [2], is one of the most common diseases of the nervous system. It affects people aged 20-40 years worldwide, although it has higher occurrence in women than in men and in those residing in northern than in southern latitudes. Despite its long history and the finding that immune cells rather than exogenous pathogens are responsible for MS development [3], the etiology of MS remains unclear.

Several treatment strategies for MS have been found to be moderately successful [4]. For example, the $\beta$-interferons and glatiramer acetate $(\mathrm{GA})$ are disease-modifying therapies with an established history of efficacy and safety in clinical practice [5-7]. In addition, monoclonal antibodies binding to specific ligands have been found effective; these include natalizumab, which binds to $\alpha 4$ integrins [8]; daclizumab, which binds to CD25 [9]; and alemtuzumab, which binds to CD52 [10]. Natalizumab and alemtuzumab have been approved by the US Food and Drug Administration for the treatment of refractory MS, while daclizumab approval is very likely in the near future. Despite their effectiveness, however, these agents have been associated with serious adverse events (SAEs), significantly restricting their further application [4]. Novel, convenient oral therapies, including fingolimod [11], teriflunomide [12], and dimethyl fumarate [13], have shown efficacy and tolerability and have been approved for the treatment of patients with MS.

However, some patients remain refractory to these agents. This may be due to as yet unknown triggers of MS, together with high heterogeneity of this disease. Therefore, searching for novel, antigen-specific immunotherapeutic treatment options for MS is highly feasible [14]. For example, myelin basic protein (MBP), the structural component of the myelin membrane, is thought to be a primary target of the immune system during MS development [15]. Attempts have been made to induce tolerance toward MBP and its structural constituents [16-20], including MBP pulsing of dendritic cells [21]. In our previous studies using a newly designed MBP epitope library, we determined that MBP peptides 46-62, 124139 and 147-170, but not 83-99, were the most immunodominant in terms of autoantibody responses in patients with MS when compared with healthy individuals and patients with other neurological diseases lacking an autoimmune background [22, 23]. Nasal administration of these MBP peptides suppressed protracted relapsing experimental allergic encephalomyelitis (EAE) in dark Agouti rats [24]. Further, selected immunodominant MBP peptides encapsulated into mannosylated liposomes were reported effective in the treatment of EAE [25]. Mannosylation of these liposomes was found critical for their therapeutic efficiency, as animals that received nonmannosylated peptide-loaded liposomes were unable to recover from the first EAE attack. The most reasonable explanation that was confirmed experimentally suggests that mannosylation of liposomes significantly enhances their uptake by dendritic cells via the CD206 receptor [25], resulting in immune system tolerance towards myelin antigens. The synergistic liposome-mediated effects of coencapsulated MBP peptides reduced overall disease course, resulting in moderate severity of attacks and faster recovery from exacerbations [25]. Preclinical studies showed that administration of the designed formulation, at doses largely exceeding those proposed for humans, did not induce significant AEs in animals. The aim of the present study was to explore the AE profile and tolerability of encapsulated MBP peptides in a cohort of patients with MS. Secondary outcomes were to evaluate the effects of these peptides on the clinical course of MS.

\section{Methods}

\section{Study Design}

This was a phase I, multicenter, open-label, dose-escalating safety, and proof-of-concept study of the oligopeptides $\mathrm{MBP}_{46-62}$, MBP ${ }_{124-139}$, and MBP ${ }_{147-170}$ coencapsulated in CD206-targeted small monolammelar liposomes (Xemys; Pharmsynthez, St. Petersburg, Russia [25]) in patients with relapsing-remitting (RRMS) or secondary progressive MS with superimposed relapses (SPMS) who failed to achieve sustained responses to first-line disease-modifying therapies (FASEMS). The FASEMS clinical trial schedule is summarized in Fig. 1A. Patients received 6 weekly subcutaneous injections, on the same day each week, of Xemys at doses ascending from $50 \mu \mathrm{g}$ to $900 \mu \mathrm{g}$. After the last injection, patients were followed up for 12 weeks.

The primary endpoint was the safety of Xemys, as determined by the frequency and severity of adverse events (AEs) and SAEs. To ensure patient safety, the patients were divided into 2 cohorts. Dose-limiting toxicities (DLT) and dose adjustments were assessed in the first cohort; doses in the second cohort were limited to the highest first-cohort dose not associated with DLT. If there were no DLTs in the first cohort, the dosing regimen would remain unaltered in the second cohort.

Secondary clinical endpoints included the number of relapses during the study period and Expanded Disability Status Scale (EDSS) score at the end of the trial. Secondary magnetic resonance imaging (MRI) endpoints included the number of gadolinium-enhancing T1 lesions and the total number of lesions in $\mathrm{T} 2$ and fluidattenuated inversion recovery (FLAIR) sequences. Laboratory endpoints included the concentrations of proand anti-inflammatory cytokines. The study was approved by the Russian Ministry of Health, the Central Ethics Commission, and all local ethic committees, and was 
Fig. 1 (A) Protocol schedule. Timeline showing major clinical and investigational elements of the study. (B) Subject allocation. Summary of screening outcome, treatment allocation, and study completion. $\mathrm{Rx}=$ treatment; EDSS = Expanded Disability Status Scale; MRI = magnetic resonance imaging; $\mathrm{MS}=$ multiple sclerosis; $\mathrm{GA}=$ glatiramer acetate; IVIg = intravenous immunoglobulin

A
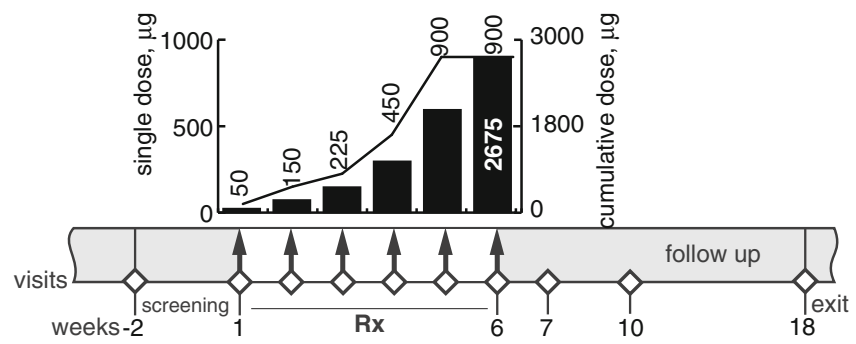

EDSS/MRI clinical evaluation

physical examination -

hematologic study

patient withdrawn

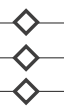

-

70 $\checkmark$
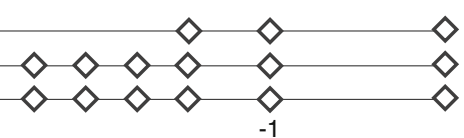

B

\begin{tabular}{|c|c|}
\hline \multicolumn{2}{|c|}{$\begin{array}{l}\text { Inclusion criteria } \\
\text { - age 18-55 diagnosed MS according McDonald criteria } 2005 \\
\text { - EDSS 3-5.5 } \\
\text { - relapses during last year }>1 \\
\text { - unsuccessful treatment by immuno-modulators/ } \\
\text { - suppressants including GA and } \beta \text {-interferons } \\
\text { - increasing of EDSS }>1.0 \text { in more than last } 6 \text { mo. } \\
\text { - stabilization }>30 \mathrm{~d} \text {. at the time of screening } \\
\text { - last dosage of GA or } \beta \text {-interferons }>30 \mathrm{~d} \text {. at the time of visit } 1 \\
\text { - negative pregnancy test }\end{array}$} \\
\hline & \\
\hline \multicolumn{2}{|c|}{\begin{tabular}{|l} 
Reasons for exclusion \\
- primary-progressive MS \\
- clinically relevant infection or surgical intervention $<30 \mathrm{~d}$. \\
at the time of screening visit \\
- body-weight index $>40 \mathrm{~kg} / \mathrm{m}^{2}$ \\
- hypersensitivity towards components of Myeloxen or GA \\
- oncology \\
- previous therapy using cladribine, alemtuzumab, rituximab, \\
natalizumab, daclizumab, IVIg \\
- previous therapy in less than 6 mo. using cyclophosphamide, \\
mitoxantrone, ciclosporin, mycophenolate mofetil, \\
azathioprine, methotrexate, plasmapheresis \\
- administration of glucocorticoids in $<1$ mo. in a daily dosage \\
equivalent to $>60 \mathrm{mg}$ of prednisolone
\end{tabular}} \\
\hline \multicolumn{2}{|c|}{ 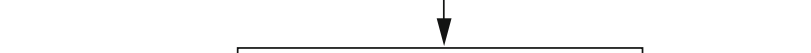 } \\
\hline & $\begin{array}{l}20 \text { patients passed } \\
\text { cohort } 01: n=10 \\
\text { cohort } 02: n=10\end{array}$ \\
\hline \\
\hline \multicolumn{2}{|c|}{$\begin{array}{l}20 \text { patients given increasing } s c \text { injections of Myeloxen } \\
\text { once weekly, } 6 \text { injections, } 2.675 \text { mg totally } \\
\text { cohort } 01: n=10 \\
\text { cohort } 02: n=10\end{array}$} \\
\hline \multicolumn{2}{|c|}{$\downarrow$} \\
\hline $\begin{array}{c}18 \text { patients completed } \\
\text { cohort } 01: \mathrm{n}=9 \\
\text { cohort } 02: \mathrm{n}=9\end{array}$ & $\begin{array}{l}2 \text { patients withdrawn } \\
\text { cohort } 01: \mathrm{n}=1 \\
\text { cohort } 02: \mathrm{n}=1\end{array}$ \\
\hline
\end{tabular}


conducted in full compliance with the Declaration of Helsinki, International Conference on Harmonisation's Good Clinical Practice, and appropriate local legislation.

\section{Subjects}

Subjects were screened 2 weeks before enrollment into the treatment phase of the study (Fig. 1B). The trial involved patients with RRMS or SPMS with superimposed relapses, defined as previously described [26]. Subjects were included if they were aged 18-55 years, had an EDSS from 3 to 5.5 and $\mathrm{a} \geq 1.0$ increase during the previous 6 months, and had $>1$ relapse during the previous year [27]. Subjects also had to be stable for $>30$ days at the time of screening and to have not received treatment with GA or $\beta$-interferons for $>30$ days at the time of visit 1 . Female subjects had to have negative pregnancy tests.

Subjects were excluded if they had primary progressive MS; clinically relevant infection or surgical intervention < 30 days before the screening visit; contraindications to MRI scanning, including hypersensitivity toward gadolinium; a body mass index $>40 \mathrm{~kg} / \mathrm{m}^{2}$; or hypersensitivity toward components of a test item (egg phosphatidylcholine, monomannosyl dioleyl glycerol, $\alpha$-tocopherol, or lactose) or GA. Subjects were also excluded if they had liver decompensation; heart diseases; tuberculosis in anamnesis; significantly abnormal hematological or biochemical parameters; oncological diseases; previous therapy with cladribine, alemtuzumab, rituximab, natalizumab, daclizumab, or intravenous immunoglobulin; treatment with any disease-modifying therapy during the previous 6 months, including cyclophosphamide, mitoxantrone, ciclosporin, mycophenolate mofetil, azathioprine, methotrexate, or plasmapheresis; or had been administered glucocorticoids within the last month at a daily dosage equivalent to $>60 \mathrm{mg}$ of prednisolone.

The study was authorized by the Russian Public Health Ministry \#930 (FASEMS-01/01) issued on 28 April 2012. All patients provided written informed consent at enrollment after discussion of the study with investigators including possible alternative treatment options. Details of full medical history and MS pathogenesis were collected.

\section{Procedures}

Lyophilized Xemys consists of equimolar amounts of lyophilized, chemically synthesized MBP peptides 46-62 (GGDRGAPKRGSGKDSHH), 124-139 (G F G Y G G R A S D Y K S A H K), and 147-170 (QGTLSKIFKLGGRDSRSGSPMARR) (total $0.45 \mathrm{mg}$ ) encapsulated in small unilamellar liposomes prepared from egg phosphatidylcholine and monomannosyl dioleyl glycerol with the addition of $\alpha$-tocopherol and lactose (total $125 \mathrm{mg}$ ). Each dose was rehydrated in $1.0 \mathrm{ml}$ sterile water immediately
Table 1 Baseline characteristics of patients with multiple sclerosis

\begin{tabular}{ll}
\hline Characteristic & Variable \\
\hline$n$ & 20 \\
Age (years) & $37.6 \pm 9.9(24-53)$ \\
Sex & \\
Weight $(\mathrm{kg})^{*}$ & $9-11(45 \%)$ \\
\hline${ }^{*}$ Average \pm SD (range) \\
${ }^{\dagger}$ Female - male (female \%)
\end{tabular}

before administration. The starting dose, consisting of 0.05 mg peptides, was chosen as the minimum to detect any unpredictable AEs without significant risk to the patients. Patients received weekly subcutaneous injections of Xemys at escalating doses over 6 weeks of $50 \mu \mathrm{g}, 150 \mu \mathrm{g}, 225 \mu \mathrm{g}, 450 \mu \mathrm{g}, 900$ $\mu \mathrm{g}$, and $900 \mu \mathrm{g}$, yielding a total dose of $2.675 \mathrm{mg}$.

Patients were followed-up 1, 4, and 12 weeks after administration of the last dose, corresponding to study weeks 7,10 , and 18 , respectively. AEs were monitored by 12-lead electrocardiography, hematology, and laboratory tests, and scored according to the Common Terminology Criteria for Adverse Events version 4.0. Any SAEs deemed "certainly" or "likely" due to the study drug were considered DLTs, with the next lowest dose level considered the maximum tolerated dose. Patients also underwent complete neurological examinations during each study visit. An MS exacerbation was defined as a new worsening of neurological function lasting for $>24 \mathrm{~h}$ that was unrelated to other comorbidities.

Table 2 Multiple sclerosis (MS) anamnesis

\begin{tabular}{ll}
\hline Anamnestic criterion & Variable $(n=20)$ \\
\hline MS type & \\
$\quad$ Relapsing-remitting & $16(80 \%)$ \\
Secondary progressive & $4(20 \%)$ \\
Baseline EDSS scores & \\
3.0 & $3(15 \%)$ \\
3.5 & $3(15 \%)$ \\
4.0 & $8(40 \%)$ \\
4.5 & $2(10 \%)$ \\
5.0 & $2(10 \%)$ \\
5.5 & $2(10 \%)$ \\
First signs of MS & $10.4 \pm 6.8(0.9-25.8)$ \\
MS diagnosis & \\
MS exacerbations during the last: & \\
1 year & $5.0 \pm 3.6(0.6-13.3)$ \\
2 years & \\
\hline Data are presented as $n(\%)$ unless otherwise indicated \\
${ }^{*}$ Average \pm SD, min-max (years) \\
${ }^{\dagger}$ Median (min-max) \\
EDSS = Expanded Disability Status Scale
\end{tabular}


Table 3 Overview of adverse events (AEs)

\begin{tabular}{ll}
\hline Total $(n=20)^{*}$ & $8(40 \%) / 16$ \\
\hline Serious AEs & 0 \\
AE, drug related & $5(25 \%) / 11$ \\
AE, led to drug interruption & 0 \\
AE, required therapy & $2(10 \%) / 2$ \\
Suspected unexpected serious adverse reactions & 0 \\
Deaths & 0 \\
\hline
\end{tabular}

* Data are presented as $n(\%) / \mathrm{c}$, where $n=$ number of subjects, $\%=$ part of subjects with $\mathrm{c}=$ number of AEs

EDSS was determined at baseline (week 2) and at all follow-up visits. Patients underwent MRI scans, including T1-weighted axial scans with and without gadolinium, proton density axial, T2-weighted axial, T2-weighted sagittal, and FLAIR sequence axial images, at baseline and at follow-up visits at weeks 7, 10, and 18. Scans were performed with Philips, Amsterdam, Netherlands Integra 1.5T, Magnetom Avanto 1.5T, and GE Medical Systems, Milwaukee, WI, USA Signa 1.5T scanners.

Serum samples for cytokine analysis were collected at baseline and during all follow-up visits. The profiles of 17 cytokines and chemokines were determined using a multiplexed fluorescent magnetic bead-based immunoassay (Bio-Rad Laboratories, Berkeley, CA, USA), according to the manufacturer's instructions. These 17 cytokines and chemokines included interleukin (IL)-1 $\beta$, IL-2, IL-4, IL-5, IL-6, IL-7, IL-8, IL-10, IL-12 (p70), IL-13, IL-17A, granulocyte colonystimulating factor, granulocyte macrophage colonystimulating factor, interferon- $\gamma$, monocyte chemoattractant protein-1 (MCP-1/CCL2), macrophage inflammatory protein (MIP-1b/CCL4), and tumor necrosis factor (TNF)- $\alpha$.

\section{Statistical Analysis}

Demographic data, baseline characteristics, safety and tolerability variables, and other parameters under investigation were calculated using descriptive statistics. Safety and tolerability were assessed in patients who received at least 1 dose of the studied substance. AEs were grouped by dose and classified by MedDRA system organ classes and preferred terms, with severity classified by Common Terminology Criteria for Adverse Events version 4.0. Secondary endpoints were analyzed in patients who received at least 1 dose of the studied substance and underwent at least 1 assessment. The normality of the data was determined using Kolmogorov-Smirnov tests; all datasets were non-normally distributed. Changes from baseline in the number of MRI lesions were assessed by analysis of variance. Mann-Whitney $t$ tests were used to compare between-group variables and the Wilcoxon signed rank test for within-group variables. All tests were two sided, and $p$ values $<0.05$ were considered significant. All statistical analyses were performed with SPSS (IBM, Armonk, NY, USA) and GraphPad Prism 6.0 (GraphPad Inc., La Jolla, CA, USA).

\section{Results}

Between April 2013 and July 2014, 20 patients with RRMS or SPMS matching all criteria were directly recruited into the trial at 4 clinical centers in the Russian Federation. Baseline characteristics of patients with MS are listed in Table 1.
Table 4 Adverse events by MedDRA preferred term and by Common Terminology Criteria for Adverse Events (CTCAE) severity grades

\begin{tabular}{lll}
\hline System organ class/preferred term & \multicolumn{2}{l}{ Grade by CTCAE 4.0* } \\
\cline { 2 - 3 } & 1 grade (mild) & 2 grade (moderate) \\
\hline Total & $6(30 \%) / 13$ & $2(10 \%) / 3$ \\
Gastrointestinal & 0 & $2(10 \%) / 2$ \\
Pain in upper abdomen & 0 & $1(5 \%) / 1$ \\
Diarrhea & 0 & $1(5 \%) / 1$ \\
General disorder and administration site conditions & $4(20 \%) / 10$ & 0 \\
Weakness & $1(5 \%) / 2$ & 0 \\
Injection site reaction & $4(20 \%) / 8$ & 0 \\
Infection and infestation & $2(10 \%) / 2$ & 0 \\
Rhinitis & $2(10 \%) / 2$ & 0 \\
Nervous system disorders & $1(5 \%) / 1$ & 0 \\
Spasm of muscles of lower extremities & $1(5 \%) / 1$ & 0 \\
Vascular disorders & 0 & $1(5 \%) / 1$ \\
Essential hypertension & 0 & $1(5 \%) / 1$ \\
\hline
\end{tabular}

* Data are presented as $n(\%) / \mathrm{c}$, where $n=$ number of subjects, $\%=$ part of subjects with $\mathrm{c}=$ number of adverse events 
Table 5 Adverse events by MedDRA preferred term and relationship to study drug

\begin{tabular}{|c|c|c|c|}
\hline \multirow[t]{2}{*}{ System organ class/preferred term } & \multicolumn{3}{|c|}{ Relationship $(n=20) *$} \\
\hline & Not related & Possible & Likely \\
\hline Total & $3(15 \%) / 5$ & $1(5 \%) / 1$ & $5(25 \%) / 10$ \\
\hline Gastrointestinal & $1(5 \%) / 1$ & 0 & $1(5 \%) / 1$ \\
\hline Pain in upper abdomen & $1(5 \%) / 1$ & 0 & 0 \\
\hline Diarrhea & 0 & 0 & $1(5 \%) / 1$ \\
\hline General disorder and administration site conditions & 0 & $1(5 \%) / 1$ & $4(20 \%) / 9$ \\
\hline Weakness & 0 & $1(5 \%) / 1$ & $1(5 \%) / 1$ \\
\hline Injection site reaction & 0 & 0 & $4(20 \%) / 8$ \\
\hline Infection and infestation & $2(10 \%) / 2$ & 0 & 0 \\
\hline Rhinitis & $2(10 \%) / 2$ & 0 & 0 \\
\hline Nervous system disorders & $1(5 \%) / 1$ & 0 & 0 \\
\hline Spasm of muscles of lower extremities & $1(5 \%) / 1$ & 0 & 0 \\
\hline Vascular disorders & $1(5 \%) / 1$ & 0 & 0 \\
\hline Essential hypertension & $1(5 \%) / 1$ & 0 & 0 \\
\hline
\end{tabular}

Inclusion and exclusion criteria, as well as the numbers of patients screened and enrolled in the study, are summarized in Fig. 1B. Of the 20 patients, $16(80 \%)$ had RRMS and 4 (20\%) had SPMS with relapses. At baseline, 3 (15\%) patients had mild disability according to EDSS score (3.0), and 17 $(85 \%)$ had moderate disability (3.5-5.5) (Table 2). Nineteen patients received all 6 weekly doses of encapsulated MBP peptides (total $2.675 \mathrm{mg}$ ) (Fig. 1A). One patient who received all 6 doses of Xemys discontinued from the study after treatment period at week 6 (his own decision); 1 patient received only the first $50-\mu \mathrm{g}$ dose and chose to discontinue after 1 week (his own decision).

As no patient experienced a DLT during treatment, an maximum-tolerated dose was not reached, making it likely to be $>900 \mu \mathrm{g}$ per week. Eight patients (40\%) experienced 16 AEs (Table 3), with 11 events in $5(25 \%)$ patients regarded as related to the Xemys injections. No SAEs, serious drug reactions, or deaths occurred during the study. Of the $16 \mathrm{AEs}, 13$, in $6(30 \%)$ patients, were regarded as grade 1 , and 3 AEs, in $2(10 \%)$ patients, were regarded as grade 2 (Table 4). No AE met the seriousness criteria of International Conference on Harmonisation E6. All drugrelated AEs were grade 1 in severity, except for diarrhea, which was grade 2 (Table 5). All AEs resolved without treatment and did not require interruption or discontinuation of the investigational drug.

The most common AE was local reaction at the site of injection, which was observed 8 times in $4(20 \%)$
Table 6 Magnetic resonance imaging (MRI) lesions by visits

\begin{tabular}{|c|c|c|c|c|c|c|c|}
\hline \multirow[t]{2}{*}{ Visit } & \multirow[t]{2}{*}{ MRI regime } & \multirow[t]{2}{*}{$n$} & \multicolumn{5}{|l|}{ MRI Lesions } \\
\hline & & & Mean $^{*}$ & Median & Min-max & Q $25 \%$ & Q $75 \%$ \\
\hline \multirow[t]{3}{*}{ Baseline } & $\mathrm{T} 1$ & 19 & $0.3 \pm 0.6$ & 0.0 & $0-2$ & 0.0 & 0.0 \\
\hline & $\mathrm{T} 2$ & & $45.2 \pm 20.0$ & 44.0 & $18-97$ & 23.0 & 60.0 \\
\hline & FLAIR & & $46.9 \pm 20.4$ & 44.0 & $21-96$ & 24.0 & 62.0 \\
\hline \multirow[t]{3}{*}{ Week 7} & $\mathrm{~T} 1$ & 18 & $1.3 \pm 1.9$ & 1.0 & $0-6$ & 0.0 & 2.0 \\
\hline & $\mathrm{T} 2$ & & $47.7 \pm 21.7$ & 47.0 & $18-101$ & 25.0 & 62.0 \\
\hline & FLAIR & & $49.2 \pm 22.1$ & 47.0 & $23-100$ & 25.0 & 67.0 \\
\hline \multirow[t]{3}{*}{ Week 10} & $\mathrm{~T} 1$ & 19 & $1.3 \pm 2.0$ & 0.0 & $0-6$ & 0.0 & 2.0 \\
\hline & $\mathrm{T} 2$ & & $47.5 \pm 22.0$ & 44.0 & $18-104$ & 28.0 & 60.0 \\
\hline & FLAIR & & $48.5 \pm 21.6$ & 44.0 & $23-103$ & 28.0 & 62.0 \\
\hline \multirow[t]{3}{*}{ Week 18} & $\mathrm{~T} 1$ & 18 & $1.3 \pm 2.8$ & 0.0 & $0-11$ & 0.0 & 1.0 \\
\hline & $\mathrm{T} 2$ & & $48.2 \pm 22.2$ & 45.0 & 19-105 & 31.0 & 60.0 \\
\hline & FLAIR & & $49.6 \pm 22.0$ & 46.0 & $24-104$ & 31.0 & 62.0 \\
\hline
\end{tabular}

* Average \pm SD

FLAIR = fluid-attenuated inversion recovery 
A

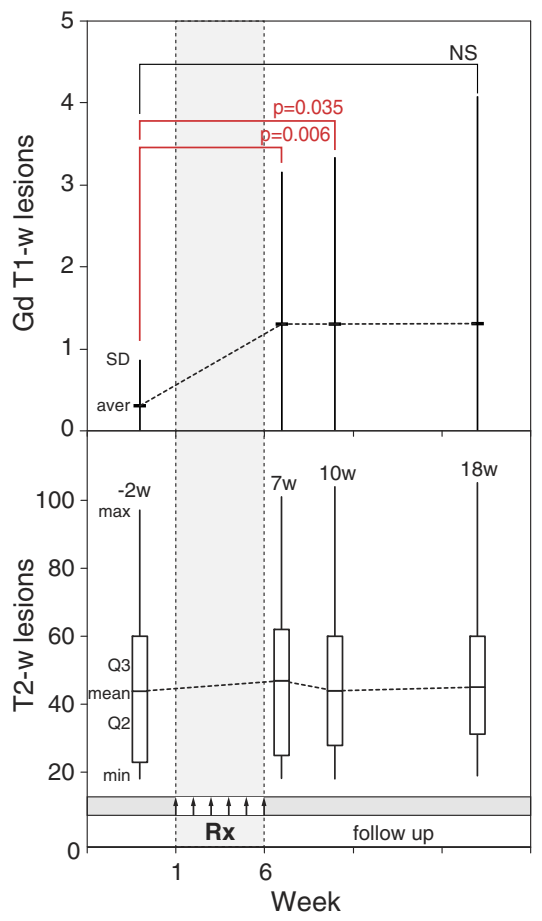

B

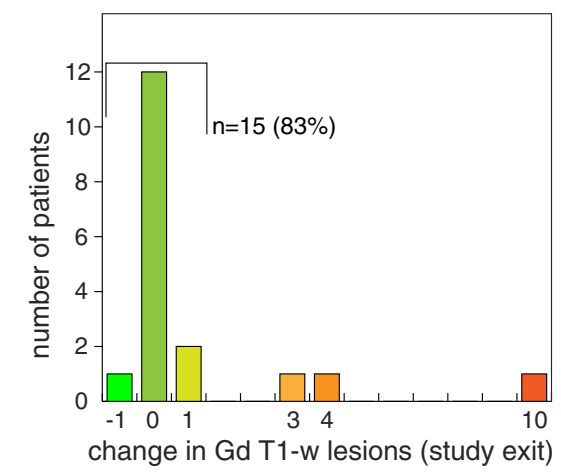

C

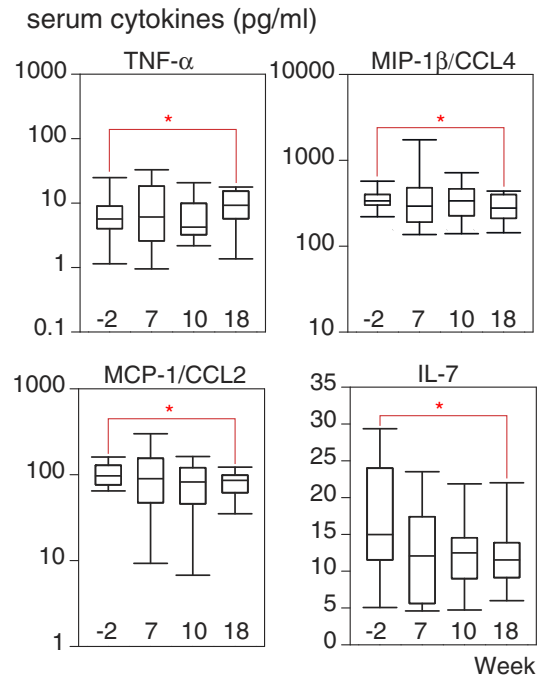

D

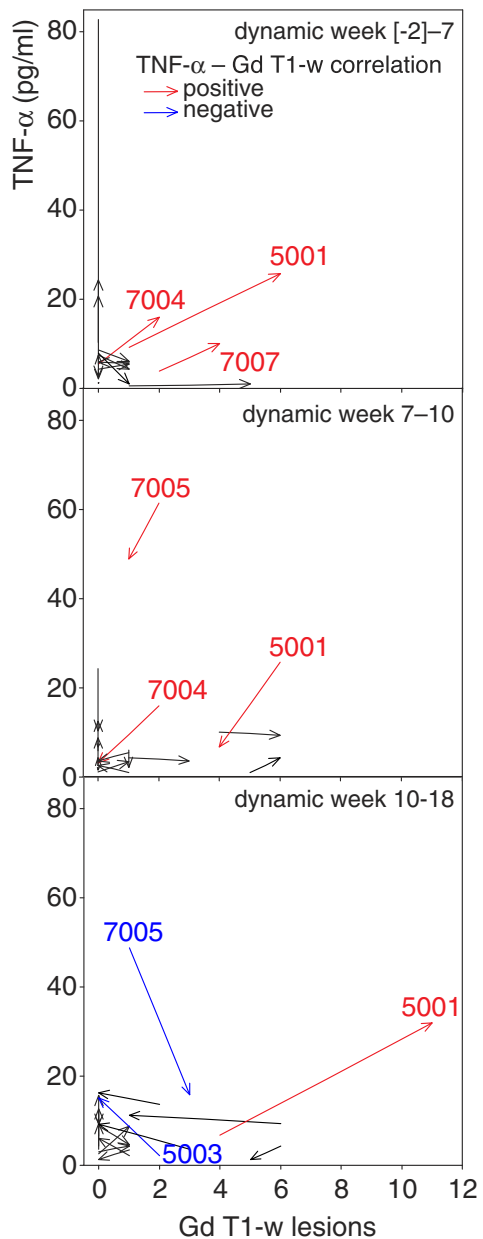

Fig. 2 (A) Cumulative change in mean number of new gadoliniumenhancing and T2-weighted (w) lesions. (B) Change in number of gadolinium (Gd)-enhancing lesions at study exit (18 weeks). (C) Concentrations of serum cytokines at screening ( -2 weeks), 7,10 , and 18 weeks. The bold lines represent the medians and the boxes represent interquartile ranges. Bars represent $95 \%$ confidence intervals. Statistically significant differences $(p<0.05)$ are indicated. (D) Vector plots showing changes in serum tumor necrosis factor (TNF)- $\alpha$ concentrations and numbers of gadolinium-enhancing lesions in studied patients. Positive and negative correlations between TNF- $\alpha$ level and number of gadolinium-enhancing lesions are shown in red and blue, respectively. Numbers represent patient identifications. Aver $=$ average; $Q=$ quartile; $\min =$ minimal value $; \max =$ maximal value MIP $=$ macrophage inflammatory protein; $\mathrm{MCP}=$ monocyte chemoattractant protein; IL = interleukin

(with and without contrast), T2, and FLAIR regimens. Nineteen patients were evaluated at baseline and week 10, and 18 patients at weeks 7 and 18 (Table 6, Fig. 2A). At baseline, $16(84 \%)$ patients had no active gadoliniumenhancing lesions. By week 7, however, active lesions were detected in $10(56 \%)$ patients, and at last follow-up, $8(33.7 \%)$ patients had active lesions. Although a trend towards an increasing number of gadolinium-enhancing lesions was detected, per subject-specific analysis of MRI results at time of study exit showed that $83 \%$ of patients had $0 \pm 1$ new lesions, with only 3 patients (17\%) having $>1$ new lesion (Fig. 2B). To assess changes in the number of MRI lesions in comparison with baseline, ANOVA was performed, with the dependent variable being the rank of the number of MRI lesions (Table 7). All datasets were non-normally distributed.

Patients underwent MRI scans at baseline (week -2) and after treatment, at weeks 7, 10, and 18, using T1-weighted 
Table 7 Gadolinium-enhancing T1 magnetic resonance imaging lesions by visits (analysis of variance)

\begin{tabular}{|c|c|c|c|c|c|c|c|}
\hline \multirow[t]{2}{*}{ Weeks } & \multirow{2}{*}{$\begin{array}{l}\text { Marginal } \\
\text { mean for } \\
\text { visits* }\end{array}$} & \multirow[t]{2}{*}{$95 \% \mathrm{CI}$} & \multicolumn{3}{|l|}{ Pared comparison } & \multirow[t]{2}{*}{$\mathrm{F}^{\ddagger}$} & \multirow[t]{2}{*}{$p^{\ddagger}$} \\
\hline & & & Difference of means ${ }^{*}, \dagger$ & $p$ & $95 \% \mathrm{CI}$ & & \\
\hline Baseline & $2.0 \pm 0.2$ & $\begin{array}{c}(1.5- \\
2.4)\end{array}$ & & & & 3.015 & 0.038 \\
\hline Week 7 & $2.8 \pm 0.2$ & $\begin{array}{c}(2.4- \\
3.3)\end{array}$ & $-0.9 \pm 0.3$ & 0.006 & $(-1.50$ to -0.27$)$ & & \\
\hline Week 10 & $2.6 \pm 0.2$ & $\begin{array}{c}(2.2- \\
3.0)\end{array}$ & $-0.7 \pm 0.3$ & 0.035 & $(-1.25$ to -0.05$)$ & & \\
\hline Week 18 & $2.4 \pm 0.2$ & $\begin{array}{c}(2.0- \\
2.9)\end{array}$ & $-0.5 \pm 0.3$ & 0.115 & $(-1.11$ to 0.12$)$ & & \\
\hline
\end{tabular}

* Data are presented $\pm \mathrm{SE}$

${ }^{\dagger}$ Difference of means between baseline and weeks 7, 10, and 18

"For "visit" factor assessment

$\mathrm{CI}=$ confidence interval

Relative to baseline, the increases in the number of active gadolinium-enhancing lesions were statistically significant at weeks 7 and $10(F=3.015, p=0.038)$, but not at week 18 ( $p>$ $0.05)$. At last follow-up, 16/19 (85\%) patients were relapsefree, and EDSS worsened in $21 \%$ and improved in $10 \%$ of patients. The disease histories, and clinical and MRI outcomes of individual patients are summarized in Table 8 .
To analyze the immunological consequences of Xemys administration, the concentrations of 17 serum cytokines and chemokines were analyzed at follow-up time points (Fig. 2C). Compared with baseline, MCP1 , MIP-1 $\beta$, and IL-7 concentrations were significantly lower and TNF- $\alpha$ was significantly higher at study exit (week 18).

Table 8 Patients' history, magnetic resonance imaging, and clinical outcome measures at study exit

\begin{tabular}{|c|c|c|c|c|c|c|c|c|}
\hline ID & Diagnosis & $\begin{array}{l}\text { Duration of } \\
\text { disease (years) }\end{array}$ & $\begin{array}{l}\text { Relapses during } \\
\text { last } 12 \text { months }\end{array}$ & $\begin{array}{l}\text { Previous } \\
\text { treatment* }\end{array}$ & $\begin{array}{l}\text { Cumulative number of } \\
\text { new Gd+ lesions }\end{array}$ & $\begin{array}{l}\text { Cumulative number of } \\
\text { new } 22 \text { lesions }\end{array}$ & $\begin{array}{l}\text { Actual } \\
\text { EDSS delta }\end{array}$ & $\begin{array}{l}\text { Relapse } \\
\text { during study }\end{array}$ \\
\hline 7001 & RRMS & 7.8 & 3 & IFN- $\beta$ & 0 & 0 & 0 & $\mathrm{~N}$ \\
\hline 7002 & RRMS & 9.9 & 2 & IFN- $\beta$ & 0 & 0 & -0.5 & $\mathrm{~N}$ \\
\hline 7004 & RRMS & 3.9 & 2 & IFN- $\beta$ & 1 & 2 & -1 & $\mathrm{~N}$ \\
\hline 7005 & RRMS & 1.5 & 2 & IFN- $\beta$ & 3 & 2 & 0 & $\mathrm{~N}$ \\
\hline 7006 & RRMS & 1.5 & 1 & IFN- $\beta$ & 0 & 2 & 0.5 & $\mathrm{Y}$ \\
\hline 7007 & RRMS & 6.5 & 2 & GA & -1 & 10 & 1 & $\mathrm{Y}$ \\
\hline 7008 & SPMS & 0.6 & 1 & IFN- $\beta$ & 0 & 0 & 0 & $\mathrm{~N}^{\mathrm{a}}$ \\
\hline 5001 & RRMS & 6.0 & 1 & IFN- $\beta$ & 10 & 0 & 0 & $\mathrm{~N}$ \\
\hline 5002 & SPMS & 9.9 & 2 & IFN- $\beta$ & 0 & 0 & 0 & $\mathrm{~N}$ \\
\hline 5003 & SPMS & 4.3 & 1 & IFN- $\beta$ & 0 & 0 & 0 & $\mathrm{~N}$ \\
\hline 4001 & RRMS & 1.4 & 1 & GA & 0 & 13 & 0 & $\mathrm{~N}$ \\
\hline 4002 & SPMS & 9.4 & 2 & IFN- $\beta$ & 0 & 9 & 0 & $\mathrm{~N}$ \\
\hline 4003 & RRMS & 2.9 & 1 & IFN- $\beta$ & 0 & 0 & 0 & $\mathrm{~N}$ \\
\hline 4004 & RRMS & 4.7 & 1 & IFN- $\beta$ & 0 & 2 & 0 & $\mathrm{~N}$ \\
\hline 4005 & RRMS & 7.2 & 3 & IFN- $\beta$ & 0 & 1 & 0 & $\mathrm{~N}$ \\
\hline 4006 & RRMS & 0.7 & 2 & IFN- $\beta$ & 0 & 1 & 0.5 & $\mathrm{~N}$ \\
\hline 4007 & RRMS & 2.6 & 2 & IFN- $\beta$ & 0 & 0 & 0 & $\mathrm{~N}$ \\
\hline 2001 & RRMS & 13.3 & 2 & GA & 1 & 1 & 0.5 & $\mathrm{~N}$ \\
\hline 2002 & RRMS & 3.2 & 3 & GA/IFN- $\beta$ & 4 & 8 & 0 & $\mathrm{Y}$ \\
\hline
\end{tabular}

* GA - glatiramer acetate

${ }^{\mathrm{a}}$ The last visit is Day 64, Day 120 is missing

EDSS = Expanded Disability Status Scale; RRMS = relapsing-remitting multiple sclerosis; IFN = interferon; GA = glatiramer acetate; SPMS = secondary progressive multiple sclerosis 


\section{Discussion}

This study showed that subcutaneous administration of Xemys was safe and well tolerated in patients with MS who had previously failed to achieve sustained disease control following treatment with GA or $\beta$-interferons. The AEs related to Xemys were of mild or moderate severity and occurred mainly after treatment with submaximal and maximal doses of Xemys. These AEs were self-limiting, required no concomitant medication, and did not cause abnormalities in blood tests or other safety measures. Taken together, these findings showed that once-weekly Xemys has a relatively good safety profile.

Patients included in the FASEMS trial have experienced significant disease activity, despite previous firstline disease-modifying treatment. Importantly, 12 weeks after the end of Xemys administration, 7 patients (37\%) showed no evidence of disease activity, and 16 (85\%) were relapse-free. Although EDSS levels and the numbers of T2-weighted lesions and new gadoliniumenhancing lesions on MRI in comparison with baseline were statistically unchanged at study exit, a statistically significant increase in the number of active gadoliniumenhancing lesions on weeks 7 and 10 in comparison with baseline was detected. Here we emphasize that all patients included in this study had experienced $>1$ relapse during the previous year, had progressing EDSS, and at the same time had disease stabilization for at least 30 days before screening. Therefore, the number of contrast-enhancing lesions may have had a natural tendency to increase during the course of the study. The lack of a placebo group reasoned by approved study design did not allow comparative monitoring of disease progression, including the number of gadoliniumenhancing lesions, in the absence of therapeutic intervention. Finally, the statistically significant increase in the number of gadolinium-enhancing lesions was assessed only in a small group of patients who experienced relapse. Thus, the appearance of these lesions was not likely associated with treatment, although this possibility cannot be completely excluded.

Our preliminary data also suggest that there were no consistent trends in serum cytokine profiles. However, the concentrations of MCP-1, MIP-1 $\beta$, and IL-7 were significantly lower after treatment that at baseline. Immunologically, Xemys administration is thought to restrict monocyte cell trafficking. Although a classical proinflammatory cytokine TNF- $\alpha$ has been previously shown to have potent beneficial effects in autoimmune neurodegeneration [28], reported herein increase in concentration of serum TNF- $\alpha$ in treated patients with MS had likely no protective input. Despite the absence of a distinct link between changes of the number of gadolinium-enhancing lesions and dynamic of serum level of TNF- $\alpha$, a rather positive correlation was observed (Fig. 2D).

In conclusion, this phase I trial showed that once-weekly subcutaneous Xemys for 6 weeks, at a cumulative dose of $2.675 \mathrm{mg}$, was safe and well tolerated by patients with RRMS and SPMS. Preclinical and clinical data warrant the further development of Xemys as an antigen-specific diseasemodifying therapy for patients with MS.

Acknowledgments This trial was sponsored by Pharmsynthez OJSC (Saint-Petersburg, Russia). A.B. Jr. and Y.L. would like to acknowledge grant RFMEFI60714X0061 from the Ministry of Education and Science of the Russian Federation for immunochemical and biochemical studies.

Required Author Forms Disclosure forms provided by the authors are available with the online version of this article.

Disclosure Evgeniy Evdoshenko has received and dedicated to research support fees for board membership, consultancy or speaking, or grants in the last 2 years from Biogen Idec, Sanofi-Avents, Genzyme, Pharmstandart, R-Pharm, Pharmsyntez, Genfa Medica, Takeda, Generium, Johnson \& Johnson, CIA Novartis, Actelion, Roche and Teva. Dmitry Genkin, Kirill Surkov, Sergey Avtushenko, Peter Kruglyakov, and Konstantin Zakharov are employees of the sponsoring company Pharmsynthez OJSC (Saint-Petersburg, Russia). Curtis Lockshin and Gregory Gregoriadis are employees of Xenetic Biosciences Inc. Gleb Makshakov has nothing to disclose.

Open Access This article is distributed under the terms of the Creative Commons Attribution 4.0 International License (http:// creativecommons.org/licenses/by/4.0/), which permits unrestricted use, distribution, and reproduction in any medium, provided you give appropriate credit to the original author(s) and the source, provide a link to the Creative Commons license, and indicate if changes were made.

\section{References}

1. Noseworthy JH, Lucchinetti C, Rodriguez M, Weinshenker BG. Multiple sclerosis. N Engl J Med 2000;343:938-952.

2. Charcot JM. Histologie de la sclérose en plaques [French]. Gazette des Hopitaux. 1868;41:554-555.

3. Rivers TM, Sprunt DH, Berry GP. Observations on attempts to produce acute disseminated encephalomyelitis in monkeys. J Exp Med 1933;58:39-53.

4. Ransohoff RM, Hafler DA, Lucchinetti CF. Multiple sclerosis-a quiet revolution. Nat Rev Neurol 2015;11:134-142.

5. Paty DW, Li DK. Interferon beta-1b is effective in relapsingremitting multiple sclerosis. II. MRI analysis results of a multicenter, randomized, double-blind, placebo-controlled trial. UBC MS/ MRI Study Group and the IFNB Multiple Sclerosis Study Group. Neurology 1993;43:662-667.

6. Johnson KP, Brooks BR, Cohen JA, et al. Copolymer 1 reduces relapse rate and improves disability in relapsing-remitting multiple sclerosis: results of a phase III multicenter, double-blind placebocontrolled trial. The Copolymer 1 Multiple Sclerosis Study Group. Neurology 1995;45:1268-1276.

7. Bornstein MB, Miller AI, Teitelbaum D, Arnon R, Sela M. Multiple sclerosis: trial of a synthetic polypeptide. Ann Neurol 1982;11:317319. 
8. Polman $\mathrm{CH}$, O'Connor PW, Havrdova E, et al. A randomized, placebo-controlled trial of natalizumab for relapsing multiple sclerosis. N Engl J Med 2006;354:899-910.

9. Gold R, Giovannoni G, Selmaj K, et al. Daclizumab high-yield process in relapsing-remitting multiple sclerosis (SELECT): a randomised, double-blind, placebo-controlled trial. Lancet 2013;381:2167-2175.

10. Cohen JA, Coles AJ, Arnold DL, et al. Alemtuzumab versus interferon beta $1 \mathrm{a}$ as first-line treatment for patients with relapsing-remitting multiple sclerosis: a randomised controlled phase 3 trial. Lancet 2012;380:1819-1828.

11. Kappos L, Radue EW, O'Connor P, et al. A placebo-controlled trial of oral fingolimod in relapsing multiple sclerosis. N Engl J Med 2010;362:387-401.

12. Confavreux $\mathrm{C}, \mathrm{O}^{\prime}$ Connor $\mathrm{P}, \mathrm{Comi} \mathrm{G}$, et al. Oral teriflunomide for patients with relapsing multiple sclerosis (TOWER): a randomised, double-blind, placebo-controlled, phase 3 trial. Lancet Neurol 2014:13:247-256.

13. Gold R, Kappos L, Arnold DL, et al. Placebo-controlled phase 3 study of oral BG-12 for relapsing multiple sclerosis. N Engl J Med 2012;367:1098-1107.

14. Farjam M, Zhang GX, Ciric B, Rostami A. Emerging immunopharmacological targets in multiple sclerosis. J Neurol Sci 2015;358:22-30.

15. Hohlfeld R, Dornmair K, Meinl E, Wekerle H. The search for the target antigens of multiple sclerosis, part 1: autoreactive CD4+ T lymphocytes as pathogenic effectors and therapeutic targets. Lancet Neurol 2015;pii:S1471-4422(15)00334-8.

16. Garren H, Robinson WH, Krasulova E, et al. Phase 2 trial of a DNA vaccine encoding myelin basic protein for multiple sclerosis. Ann Neurol 2008;63:611-620.

17. Katsara M, Deraos G, Tselios T, et al. Design and synthesis of a cyclic double mutant peptide (cyclo(87-99)[A91,A96]MBP87-99) induces altered responses in mice after conjugation to mannan: implications in the immunotherapy of multiple sclerosis. J Med Chem 2009;52:214-218.
18. Katsara M, Yuriev E, Ramsland PA, et al. A double mutation of MBP(83-99) peptide induces IL-4 responses and antagonizes IFNgamma responses. J Neuroimmunol 2008;200:77-89.

19. Peschl P, Reindl M, Schanda K, Sospedra M, Martin R, Lutterotti A. Antibody responses following induction of antigen-specific tolerance with antigen-coupled cells. Mult Scler 2015;21:651-655.

20. Lutterotti A, Yousef S, Sputtek A, et al. Antigen-specific tolerance by autologous myelin peptide-coupled cells: a phase 1 trial in multiple sclerosis. Sci Transl Med 2013;5:188ra75.

21. Liu X, Ciumas C, Huang YM, et al. Autoantigen-pulsed dendritic cells constitute a beneficial cytokine and growth factor network in ameliorating experimental allergic encephalomyelitis. Mult Scler 2005;11:381-389.

22. Belogurov AA, Jr., Kurkova IN, Friboulet A, et al. Recognition and degradation of myelin basic protein peptides by serum autoantibodies: novel biomarker for multiple sclerosis. J Immunol 2008;180:1258-1267.

23. Ponomarenko NA, Durova OM, Vorobiev, II, et al. Autoantibodies to myelin basic protein catalyze site-specific degradation of their antigen. Proc Natl Acad Sci U S A 2006;103:281-286.

24. Belogurov AA, Jr., Zargarova TA, Turobov VI, et al. Suppression of ongoing experimental allergic encephalomyelitis in DA rats by novel peptide drug, structural part of human myelin basic protein 46-62. Autoimmunity 2009;42:362-364.

25. Belogurov AA, Jr., Stepanov AV, Smirnov IV, et al. Liposomeencapsulated peptides protect against experimental allergic encephalitis. FASEB J 2013;27:222-231.

26. Polman $\mathrm{CH}$, Reingold SC, Edan G, et al. Diagnostic criteria for multiple sclerosis: 2005 revisions to the "McDonald Criteria". Ann Neurol 2005;58:840-846.

27. Kurtzke JF. Rating neurologic impairment in multiple sclerosis: an expanded disability status scale (EDSS). Neurology 1983;33:14441452.

28. Liu J, Marino MW, Wong G, et al. TNF is a potent antiinflammatory cytokine in autoimmune-mediated demyelination. Nat Med 1998;4:78-83. 